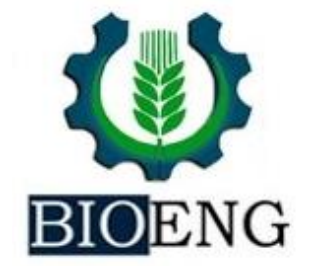

\section{AVALIAÇÃO DO DESEMPENHO TÉRMICO DE BEZERREIROS COM ECO-FORRO DE PARTÍCULAS DE MADEIRA E FIBRA DE SISAL}

\author{
M. R. Cabral", E. Y. Nakanishi, J. Fiorelli, H. Savastano Jr
}

USP - Univ de São Paulo, Faculdade de Zootecnia e Engenharia de Alimentos, Campus de Pirassununga, SP, Brasil

Article history: Received 26 June 2017; Received in revised form 28 August 2017; Accepted 30 August 2017; Available online 29 September 2017.

\title{
RESUMO
}

Este trabalho teve como objetivo avaliar o potencial de utilização do eco-forro constituído de painéis de partículas de madeira de maravalha de Pinus spp. e fibras de sisal aglutinados com resina poliuretana à base de óleo de mamona (PU-mamona) quando aplicados em bezerreiros cobertos com telhas de fibrocimento. Nesse estudo foi aferida a temperatura interna do bezerreiro, temperatura de globo negro, umidade relativa, no período da primavera, durante 21 dias e determinados os índices de conforto ITGU, ITU e CTR. Os resultados obtidos indicaram que a temperatura de globo negro e os índices de conforto ITGU e CTR dos bezerreiros com ecoforro foi inferior àquelas aferidas em bezerreiros desprovido de forro. As imagens termográficas comprovaram que o eco-forro diminuí a transferência de calor e radiação para o interior da instalação.

Palavras-chave: Ambiência; agroindústria; bovinos; Produção leiteira.

\section{EVALUATION OF THE THERMAL PERFORMANCE OF CALVES' SHELTER WITH ECO-LINING OF WOOD PARTICLES AND SISAL FIBER}

\begin{abstract}
The aim of this study was to evaluate the potential usage of the eco-lining consisting of particleboards of Pinus spp. wood and sisal fibers bonded with polyurethane castor oil resin, when applied to calf-shelters covered with asbestos cement tiles. In this study, the internal temperature of the shelter, black globe temperature and relative humidity in the spring period were measured during 21 days and the ITGU, ITU and CTR comfort indexes were determined. The results indicated that the black globe temperature and the ITGU and CTR comfort indices of the eco-lining were inferior to those measured in heifers without lining. The thermographic images proved that the eco-lining decreased the transfer of heat and radiation to the interior of the installation.
\end{abstract}

Keywords: Ambience; cattle; dairy production; Particleboard; agroindustry.

*matheusrc@usp.br 


\section{INTRODUÇÃO}

Segundo dados do Ministério da Agricultura Pecuária e AbastecimentoMAPA (2016) o agronegócio brasileiro é o setor da economia que vem contribuindo significativamente com o crescimento do país e é um dos responsáveis pelo superávit na balança comercial. As exportações do setor somaram US\$ 6,71 bilhões, tal valor corresponde a 50,3\% das vendas externas totais do país. Devido a este aumento, a produção leiteira, por exemplo, ocupou a quinta posição no cenário mundial em 2013.

No entanto, embora as projeções futuras apresentem-se favoráveis, a produção leiteira se depara com desafios que impedem o expressivo aumento de produtividade. Tais como a alta temperatura e a alta umidade, fatos típicos do clima brasileiro, que apresentam influência significativa no desenvolvimento, na produção e na reprodução dos animais (VASCONCELOS \& DEMETRIO, 2011).

$\mathrm{Na}$ criação leiteira, o aleitamento é considerado a etapa mais onerosa, pois os custos diários são maiores do que em qualquer outra fase. $\mathrm{O}$ alto custo está relacionado a alimentação líquida fornecida, como também, ao manejo dos animais (VASCONCELOS et al., 2009). Contudo, uma alimentação excelente e custosa não pode trazer maiores índices de produção se o animal estiver em condições ambientais desfavoráveis. De acordo com STULL \& REYNOLDS (2008) a temperatura máxima ideal de conforto térmico para bezerros é de $25^{\circ} \mathrm{C}$. Isto é, caso a temperatura esteja acima do estabelecido ao conforto, o bezerro não dissipa o calor metabólico suficiente para manter a homeostase, o que acarreta na diminuição da ingestão de alimento, e proporciona menor ganho de peso diário (NĚMEČKOVÁ et al., 2013).

Portanto, durante a fase do aleitamento, as instalações são fundamentais, pois facilitam o manejo e protegem os animais contra as intempéries. Bezerreiros inadequados podem expor os animais à condições climáticas adversas, resultando em um ambiente não favorável para o seu bem-estar como, por exemplo, um ambiente com temperatura elevada, excesso de umidade, baixa ventilação, altas concentrações de amônia ocasionada pela falta de higiene podem acarretar na elevação dos índices de diarreia e em problemas respiratórios, principais fatores que resultam na mortalidade nos animais (CASTRO et al., 2010).

Alguns ajustes de projeto podem auxiliar na diminuição da temperatura interna do ambiente e aumento do conforto térmico, como por exemplo, o tipo de material utilizado nas instalações ou o uso de estratégias simples como exposição da instalação à sombra (TINÔCO, 2001). FIORELLI et al. (2012) avaliaram diferentes coberturas em abrigos individuais para bezerros expostos ao sol e a sombra e concluíram que os melhores índices de conforto térmico para bezerreiros foram obtidos nas instalações expostos à sombra, pois segundo os autores o sombreamento natural proporciona um microclima mais confortável aos animais.

Barnabé et al. (2013) investigaram a temperatura superficial de materiais utilizados para cobertura (palha de palmeira, telha polimérica reciclada e fibrocimento) individual de bezerreiros. Os autores constataram o desempenho térmico inferior para a cobertura de fibrocimento, revelando a importância do material empregado nesse tipo de construção rural.

Outra alternativa é o uso de forro sob a cobertura, usualmente empregada em granjas aviárias. O forro é uma estrutura indispensável na maioria das construções, atuando como segunda barreira térmica, protegendo dos raios solares incidentes, reduzindo assim a temperatura interna da instalação (TINÔCO, 2001). O uso do forro em granjas de frango, por exemplo, proporciona um consumo de ração mais adequado pelos animais e 
consequentemente, em ganho de peso quando comparado com animais alojados em instalações desprovidas de forro (ABREU et al., 2007).

O forro não se restringe apenas ao uso de lonas, estudos com materiais não convencionais, como painéis produzidos com subprodutos agroindustriais, vêm sendo avaliado no meio acadêmico e resultados satisfatórios de redução de temperatura interna e dos índices de conforto térmico foram obtidos (CRAVO et al., 2015, BARBIRATO et al. 2015).

A produção de painéis de partículas com resíduos lignocelulósicos e fibras naturais se mostra como uma opção para

\section{MATERIAL E MÉTODOS}

\section{Fabricação do eco-forro}

O processo de fabricação do eco-forro foi iniciado com a secagem das partículas de maravalha de Pinus spp. e das fibras de sisal em estufa com circulação de ar forçada, a $60^{\circ} \mathrm{C}$, até atingir teor de umidade de $10 \%$ (EMBRAPA, 2010). O processamento das fibras de sisal foi realizado em moinho de facas (modelo MB-20, Astecma), com peneira de até $10 \mathrm{~mm}$ de comprimento. Posteriormente, ambas as matérias primas foram classificadas separadamente em um agitador automático (modelo $\mathrm{G}$, Produtest, Brasil) para obter partículas de maravalha e fibras de sisal com comprimentos de $10 \mathrm{~mm}$.

Os painéis de partículas utilizados para montagem do eco-forro foram produzidos com densidade de $500 \mathrm{~kg} \cdot \mathrm{m}^{-3} \mathrm{e}$ dimensões finais de $55 \mathrm{~cm} \times 55 \mathrm{~cm} \times 1 \mathrm{~cm}$, seguindo a metodologia de produção descrita por CABRAL et al. (2017). A formulação dos painéis de partículas conteve o teor de $75 \%$ de resíduo de madeira e $25 \%$ de fibra de sisal em massa, e a proporção da resina poliuretana de mamona (PU-mamona) utilizada foi de $12 \%$ sobre a massa total seca.

Os parâmetros produtivos adotados foram $100^{\circ} \mathrm{C}$ de temperatura e $5 \mathrm{MPa}$ de pressão por $10 \mathrm{~min}$. Após finalizada a agregar valor à estes materiais (CABRAL et al. 2017), possibilitando atender à crescente demanda da indústria de painéis de madeira, além de contribuir com a diminuição do uso da madeira e, consequentemente, com a pressão sobre os ecossistemas naturais, reduzindo o custo de produção dos painéis, tornando-os mais competitivos no cenário econômico (MENDES et al., 2010).

Dentro desse contexto, o presente trabalho teve como objetivo avaliar bezerreiros individuais com forro de painéis de partículas de maravalha de Pinus spp. e fibras de sisal aglomeradas com resina poliuretana à base do óleo de mamona.

prensagem, os painéis foram armazenados em temperatura ambiente por $72 \mathrm{~h}$ para a finalização da cura do adesivo. Após $72 \mathrm{~h}$ foi realizada a montagem do eco-forro constituído de painéis de partículas no bezerreiro.

\section{Avaliação dos bezerreiros}

$\mathrm{O}$ estudo foi conduzido nas dependências do setor de gado leiteiro da Faculdade de Zootecnia e Engenharia de Alimentos, Universidade de São Paulo, localizado em Pirassununga, SP, Brasil (altitude de $630 \mathrm{~m}$, coordenadas 21 $57^{\circ} 02^{\prime \prime}$ de latitude sul e $47^{\circ} 27^{\prime} 50^{\prime \prime}$ de longitude oeste, clima tropical de altitude-Cwa). Os bezerreiros possuíam as seguintes dimensões: 1,20 $\mathrm{m}$ de largura, 1,50 $\mathrm{m}$ de profundidade e $1,10 \mathrm{~m}$ de altura. As laterais estavam fechadas com 3 placas de madeira, pintadas de branco com cal, possuindo uma única abertura, voltada para o leste. O substrato utilizado foi areia grossa, o mesmo adotado no setor de bovino de leite onde foi realizado o projeto. E tem como finalidade evitar umidade e mal cheiro advindos de urina e fezes do animal, além de facilitar o manejo e evitar calos nos bezerros. A cobertura era constituída de telhas de fibrocimento de $5 \mathrm{~mm}$. No presente 
experimento foram avaliados dois bezerreiros distintos, sendo o tratamento B1 o bezerreiro referência, sem eco-forro
(Figura 1.B1) e o tratamento com eco-forro (Figura 1.B2).
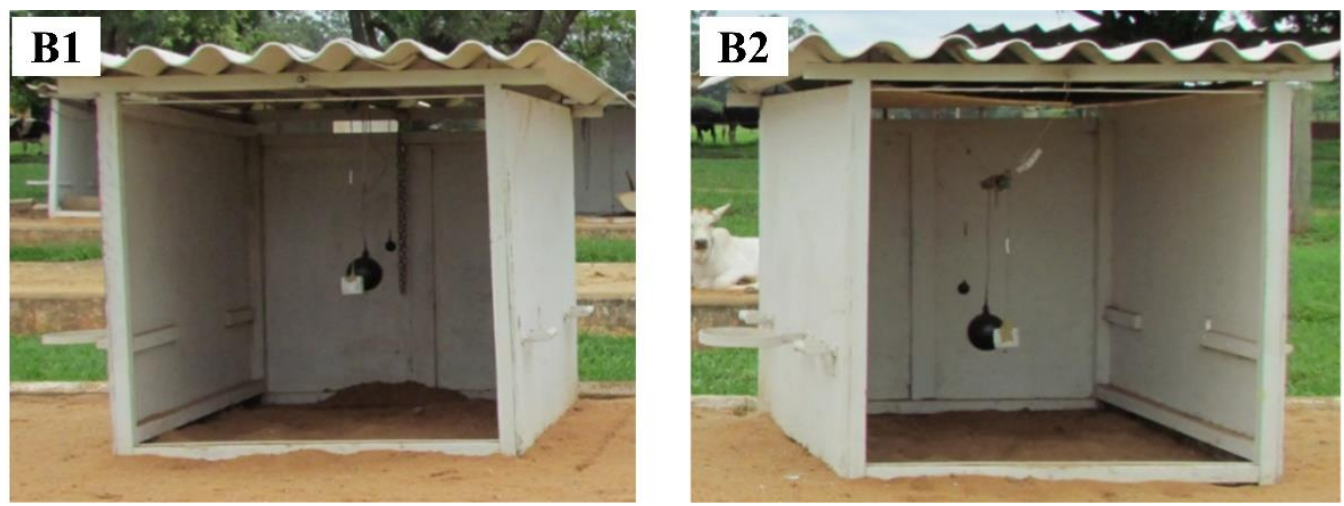

Figura 1. Bezerreiros experimentais: sem eco-forro (B1); com eco-forro (B2)

As coletas de dados ocorreram no período de 05 de setembro a 05 de outubro de 2013 estipuladas nos horários das $10 \mathrm{~h}$ às $16 \mathrm{~h}$ com intervalo de uma hora. Foram coletados os valores de temperatura do ar, umidade relativa e temperatura de globo negro (TGN), por meio do aparelho datalogger, em conjunto com globo negro posicionado no centro geométrico dos bezerreiros.

A temperatura de globo foi utilizada, pois esta variável estima valores aproximados de estresse causado pelo efeito combinado da energia térmica radiante, da

\section{Índice de Temperatura e Umidade}

$\mathrm{O}$ índice de temperatura e umidade (ITU) foi calculado como proposto por temperatura do ar e velocidade do vento, sendo ela própria caracterizada como uma medida de conforto térmico, supondo não haver trocas térmicas de evaporação entre o animal e o ambiente (TAKAHASHI et al., 2009). A velocidade do vento foi aferida na região do experimento, com auxílio de um anemômetro digital (marca INCOTERM ${ }^{\circledR}$ ). Com base nos dados coletados, foram determinados os índices de temperatura e umidade (ITU), carga térmica radiante (CTR) e índice de temperatura de globo negro e umidade (ITGU).

DIKMEN \& HANSEN (2009) (Eq.1), em que, $\mathrm{T}_{\mathrm{bs}}=$ temperatura de bulbo seco $\left({ }^{\circ} \mathrm{C}\right)$; $\mathrm{UR}=$ umidade relativa $(\%)$.

$$
\mathrm{ITU}=\left(1,8 \mathrm{xT}_{\mathrm{bs}}\right)-\left[(0,55-0,0055 \mathrm{xUR}) \mathrm{x}\left(1,8 \mathrm{xT}_{\mathrm{bs}}-26,8\right)\right] \quad \text { Eq. } 1
$$

\section{Carga Térmica Radiante}

A Carga Térmica Radiante (CTR) seguiu a equação proposta por ESMAY
(1969) (Eq.2), em que, $\delta=5,67$ x 10-8 Wm2K-4 (constante de Stefan-Boltzman); TMR $=$ Temperatura Média Radiante (Eq.3).

$$
\begin{array}{cc}
\mathrm{CTR}=\delta(\mathrm{TMR})^{4} & \text { Eq. } 2 \\
\mathrm{TMR}=100\left[2.51 \times(\mathrm{Vv})^{0,5} \times\left(T_{g}-T_{a}\right)+\left(\frac{T_{g}}{100}\right)^{4}\right]^{1 / 4} & \text { Eq. } 3
\end{array}
$$


Em que, $\mathrm{Vv}=$ Velocidade do vento $(\mathrm{m} / \mathrm{s}) ; \mathrm{Ta}$ $=$ Temperatura ambiente $(\mathrm{K}) ; \mathrm{Tg}=$

Índice de Temperatura de Globo negro e Umidade (ITGU)

$\mathrm{O}$ índice de globo negro e umidade utilizado, foi baseado na combinação de fatores: temperatura de bulbo seco, umidade, radiação e movimento do ar. Sendo um indicador de conforto térmico animal mais
Temperatura de globo negro (K).

preciso que o ITU em condições de estresse térmico, quando há a incidência solar no ambiente (BUFFINGTON \& COLLAZOAROCHO, 1981).

Para o cálculo do ITGU foi utilizada a Eq. 4 (BUFFINGTON \& COLLAZOAROCHO, 1981).

$$
\mathrm{ITGU}=T_{g}+0,36 t_{o}+41,5
$$

Onde, $\mathrm{Tg}=$ Temperatura de Globo Negro $\left({ }^{\circ} \mathrm{C}\right) ; \mathrm{To}=$ Temperatura do Ponto de Orvalho $\left({ }^{\circ} \mathrm{C}\right)$ (Eq.5)

$$
t_{o}=\frac{237,3 \ln ^{e_{a}} / A}{17,3-\ln ^{e_{a}} / A}
$$

Onde, $e_{a}=$ pressão do vapor atual do ar (Eq.6); $A=$ constante (610,8 Pa)

$$
e_{a}=e_{s} x U R
$$

Onde, $e_{\mathrm{s}}=$ pressão de vapor saturado $(\mathrm{Pa})(\mathrm{Eq} .7)$

$$
e_{s}=A \cdot \exp ^{\frac{17,3 t}{237,3+t}}
$$

Onde, $\mathrm{t}=$ temperatura

\section{Imagem térmica}

As análises térmicas das temperaturas das superfícies internas das instalações foram realizadas por Termovisor, por meio do equipamento FLUKE, modelo ti20 thermal imager e realizadas no período crítico do dia (entre $11 \mathrm{~h}$ e 13h). A interpretação dos resultados ocorreu por meio do uso do software IRSoft, desenvolvido pela marca Testo, sendo identificado variações de temperatura, na superfície inferior da telha (B1) e na superfície inferior do eco-forro (B2), conforme ilustra a figura 1.

\section{RESULTADOS E DISCUSSÃO}

Durante o período de estudo, a média de temperatura do local onde os bezerreiros

\section{Análise estatística dos dados}

Foi realizada a análise descritiva das variáveis climáticas (temperatura, umidade e temperatura de globo - TGN) e dos índices de conforto térmico (ITU, ITGU e CTR). Os dados foram submetidos a uma análise inferencial para diagnosticar a existência de diferença significativa entre os tratamentos. Foi realizado um delineamento inteiramente casualizado (DIC) e os dados comparados pelo teste Tukey quando a ANOVA foi significativa, sendo ambos testados a $\mathrm{p}<0,05$.

foram alocados foi de $24,4^{\circ} \mathrm{C}$ e umidade relativa de $62 \%$. Pode ser observado, por 
meio da Figura 2, que a média das temperaturas do ambiente entre $13 \mathrm{~h}-17 \mathrm{~h}$ estava acima da temperatura crítica indicada para bezerros ( $\mathrm{T}$ acima de $26^{\circ} \mathrm{C}$ ) (AZEVÊDO \& ALVES, 2009), bem como a umidade nesses horários foi de aproximadamente 50\%. Ainda segundo os autores estes valores de temperatura acima de $26^{\circ} \mathrm{C}$ e umidade relativa alta podem resultar em estresse por calor nos animais.

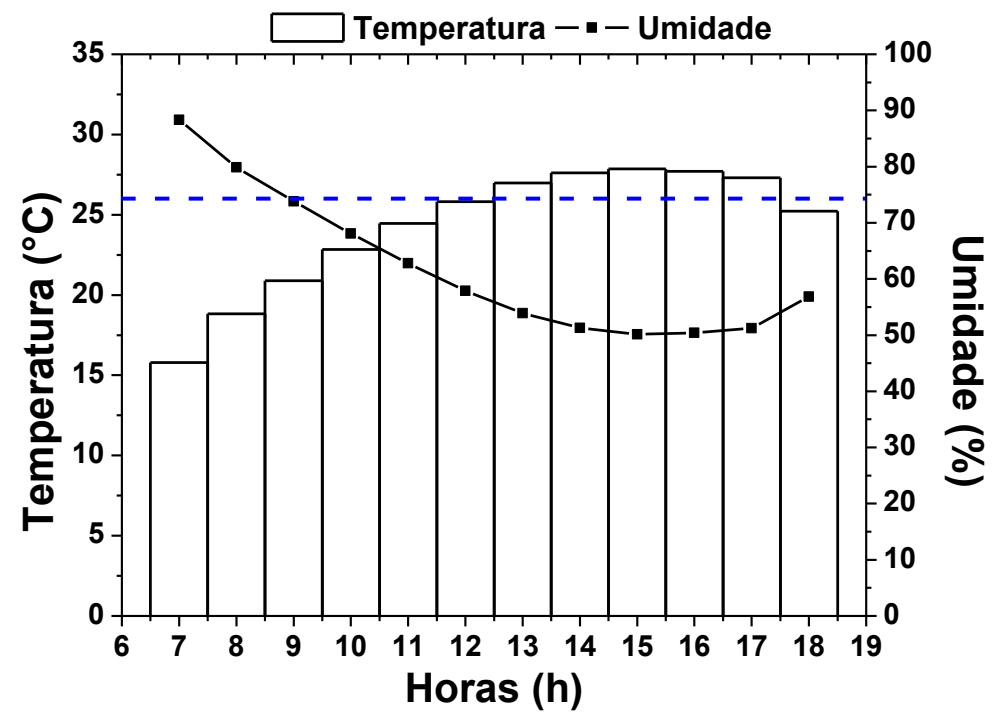

Figura 2. Valores médios de temperatura e umidade do ambiente. Linha tracejada= Temperatura crítica para bezerros (AZEVÊDO \& ALVES, 2009)

\section{Avaliação do ambiente interno do bezerreiro}

O bezerreiro é uma estrutura pequena comparando às instalações planejadas para regiões de clima tropical com pé direito de no mínimo 3 metros. Sendo assim, o calor transmitido da telha para o ambiente interno é maior, principalmente nas horas mais quentes do dia, podendo influenciar nos índices de conforto térmico.

Foi observado neste estudo por meio da análise de variância (ANOVA), que os resultados obtidos não apresentaram significância na interação dos fatores: tipo de bezerreiro (B1 e B2) e horas (10:00, 11:00, $12: 00, \quad 13: 00, \quad 14: 00, \quad 15: 00, \quad 16: 00 \quad h)$ ( $\mathrm{p}>0,05)$, portanto, foi avaliado apenas $\mathrm{o}$ fator tipo de bezerreiro. Na Tabela 1 estão apresentados os valores médios das variáveis ambientais e índices calculados para cada bezerreiro.

Pode ser observado que as variáveis temperatura, umidade e o ITU não apresentaram diferença significativa entre os bezerreiros referência e com forro ( $>>0,05)$, ressaltando que o estudo foi realizado na primavera, o que pode ter influenciado na não diferenciação entre os ambientes.

De acordo com ARMSTRONG (1994) os valores encontrados nesse estudo para o ITU (Tabela 1), em ambos os bezerreiros, podem representar que o animal passaria por um estresse térmico pequeno ou brando, pois esta variável encontra-se na faixa de 72 a 78 . $\mathrm{O}$ estresse térmico seria considerado como moderado se o valor de ITU estivesse na faixa de 79 a 88 , e severo, caso apresentasse valores na faixa de 89 a 98 . 
Tabela 1. Valores médios de temperatura dentro do bezerreiro, umidade, TGN, ITU, CTR e ITGU

\begin{tabular}{ccccccc}
\hline Bezerreiro & $\begin{array}{c}\text { Temperatura interna } \\
\text { bezerreiro } \\
\left({ }^{\circ} \mathrm{C}\right)\end{array}$ & $\begin{array}{c}\text { Umidade } \\
(\%)\end{array}$ & TGN & ITU & $\begin{array}{c}\text { CTR } \\
\left(\mathrm{W} / \mathrm{m}^{2}\right)\end{array}$ & ITGU \\
\hline B1 & $29,0^{\mathrm{a}}$ & $46,8^{\mathrm{a}}$ & $29,9^{\mathrm{a}}$ & $76,1^{\mathrm{a}}$ & $487,1^{\mathrm{a}}$ & $76,9^{\mathrm{a}}$ \\
B2 & $29,1^{\mathrm{a}}$ & $47,7^{\mathrm{a}}$ & $28,7^{\mathrm{b}}$ & $76,4^{\mathrm{a}}$ & $471,9^{\mathrm{b}}$ & $75,9^{\mathrm{b}}$ \\
\hline
\end{tabular}

*Médias seguidas pela mesma letra na coluna não diferem significativamente em $5 \%$ pelo teste de Tukey

A temperatura de globo negro (TGN) aferida entre 10:00 e 16:00 h no bezerreiro referência (B1) apresentou diferença significativa quando comparada com àquela do bezerreiro com forro (B2) $(\mathrm{p}<0,05)$. O uso do eco-forro resultou em uma diminuição de $1,2^{\circ} \mathrm{C}$.

Em teoria, no ambiente, os bezerreiros foram expostos a radiação direta do sol e a radiação indireta, emitidas do solo ou objetos. A radiação solar direta tem grande influência no ambiente interno, pois uma parte dessa radiação incidente é refletida, enquanto que uma outra parte é absorvida pela cobertura e é transmitida para o interior do bezerreiro (Figura 3 ).

Dessa forma, o eco-forro atua como isolante, pois proporciona a formação de um colchão de ar entre a telha e o ambiente interno. Portanto, a radiação transmitida pela telha (d), encontra um segundo obstáculo (eco-forro), sendo parte desta radiação refletida (e), enquanto outra parte absorvida ou transmitida para o ambiente interno (c) (Figura 3).

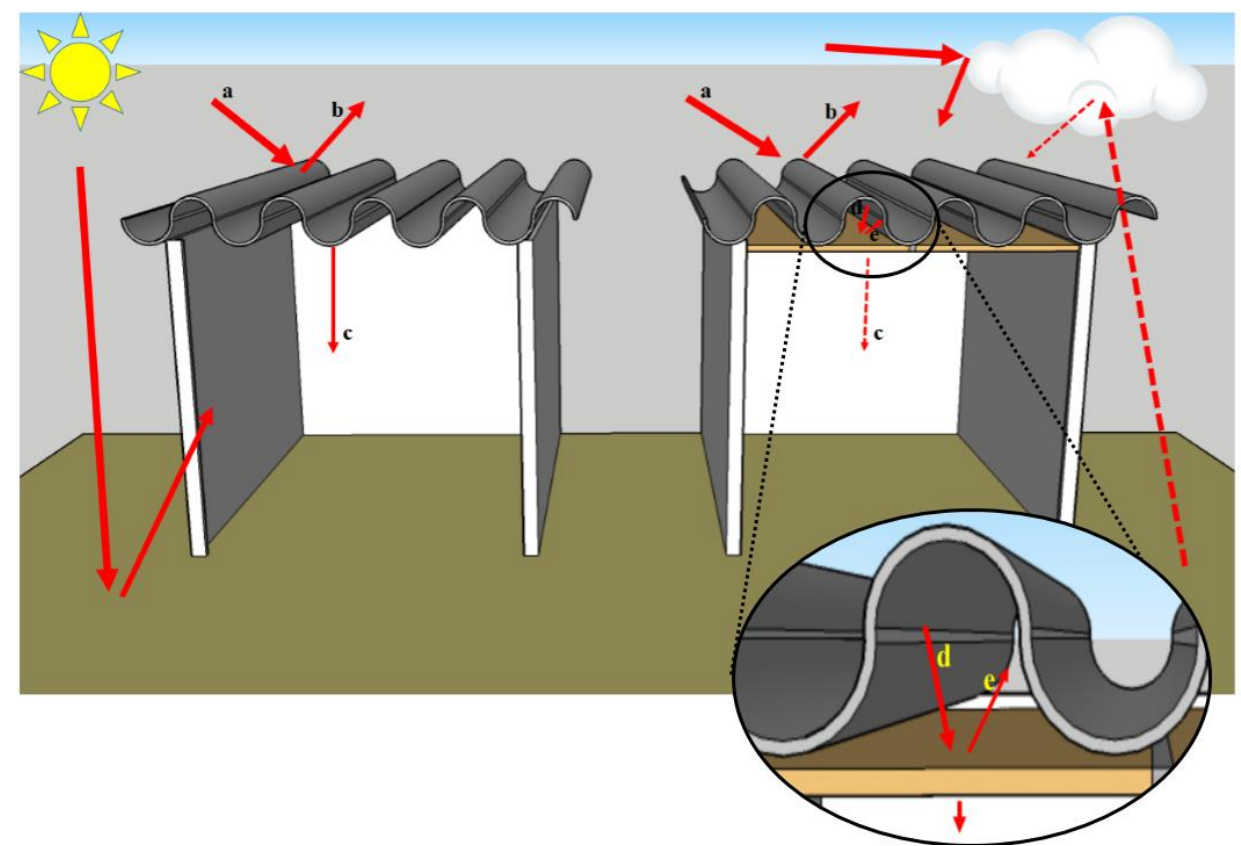

Figura 3. Representação esquemática da incidência do sol em bezerreiros

Os índices CTR e ITGU (Tabela 1) aferidos no bezerreiro sem forro (B1) foram superiores e estatisticamente diferentes $(\mathrm{p}<0,05)$ quando comparados com os índices coletados no bezerreiro com eco-forro (B2).

Quanto maior o valor da CTR, mais desfavoráveis são as condições ambientais 
para criação de animais. A CTR média no bezerreiro sem eco-forro (B1) e com ecoforro (B2) foram, respectivamente, $487,1 \mathrm{~W} / \mathrm{m}^{2}$ e $471,9 \mathrm{~W} / \mathrm{m}^{2}$ demonstrando que $\mathrm{o}$ uso do eco-forro acarretou em uma redução média de $15,2 \mathrm{~W} / \mathrm{m}^{2}$ na $\mathrm{CTR}$, diferenciando dos valores determinados por KAWABATA et al. (2005) que ao avaliar bezerreiros com telhado duplo de fibrocimento com distância de $5 \mathrm{~cm}$ entre as telhas, formando um colchão de ar não foi identificada diferença significativa entre os valores da CTR quando comparada com bezerreiros referência (KAWABATA et al., 2005).

Os valores de ITGU são classificados de acordo com a situação térmica dos bezerros, sendo considerado valores de ITGU até 74 como situação de conforto térmico para os animais; de 74 até 78 identificam situação de alerta; de 79 a 84 situação de perigo; acima de 84 grau de emergência para acondicionamento de bovinos (BAÊTA \& SOUZA, 1997).

Nesse estudo, é possível observar que o ITGU aferido nos bezerreiros B1 e B2 estão classificados na zona de alerta (entre 74 a 78) para criação de bovinos, no entanto, no tratamento B2, a presença do eco-forro representou uma redução significativa no valor de ITGU $(p<0,05)$, em comparação com os dados coletados no B1. A Figura 4 apresenta os valores de ITGU nos dois bezerreiros analisados. Pode-se observar para o horário mais crítico 13:00 e 14:00 h, o ITGU no bezerreiro sem eco-forro (B1) esta tangenciando a zona de perigo para o animal. Considerando que a época analisada foi a primavera, isso pode ser um alerta, principalmente para o período do verão e o uso de forro pode proporcionar um ambiente mais adequado para a criação de bezerros.

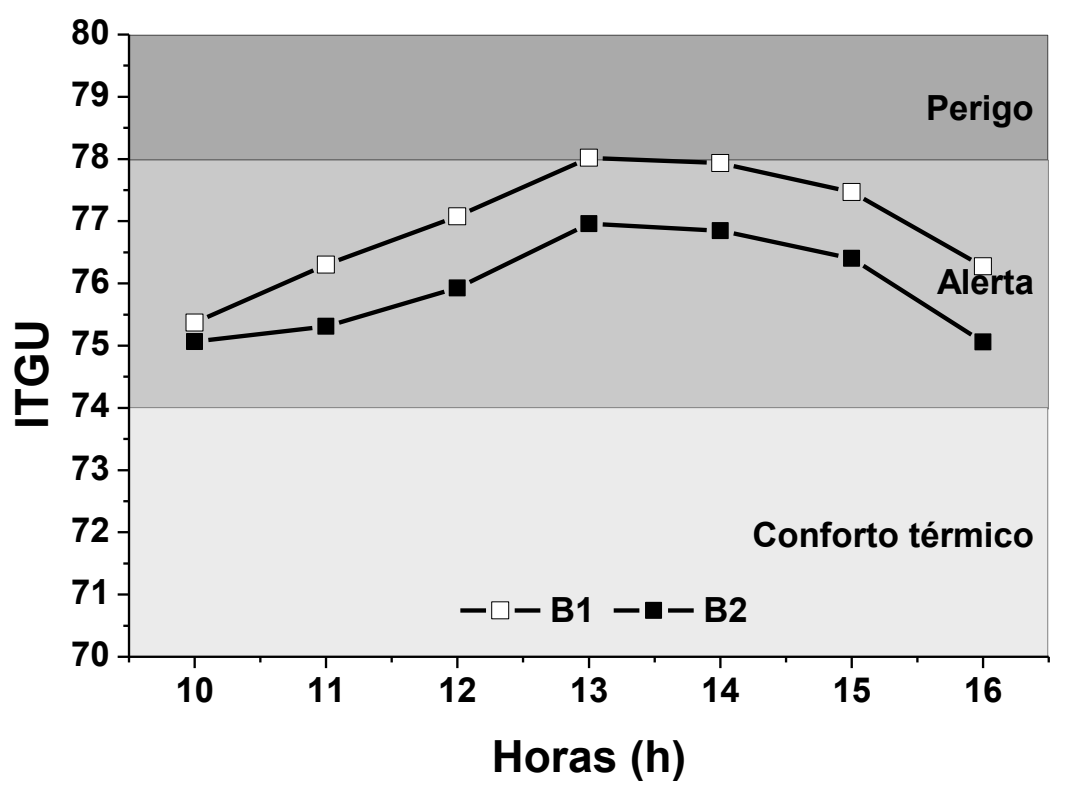

Figura 4. Valores médios de ITGU para os bezerreiros sem eco-forro (B1) e com eco-forro (B2)

Análise interna com Termovisor

$\mathrm{Na}$ Figura 5 estão apresentadas as imagens termográficas obtidas por meio da câmera termográfica na região da superfície inferior da telha (B1) e da superfície inferior do eco-forro (B2). 


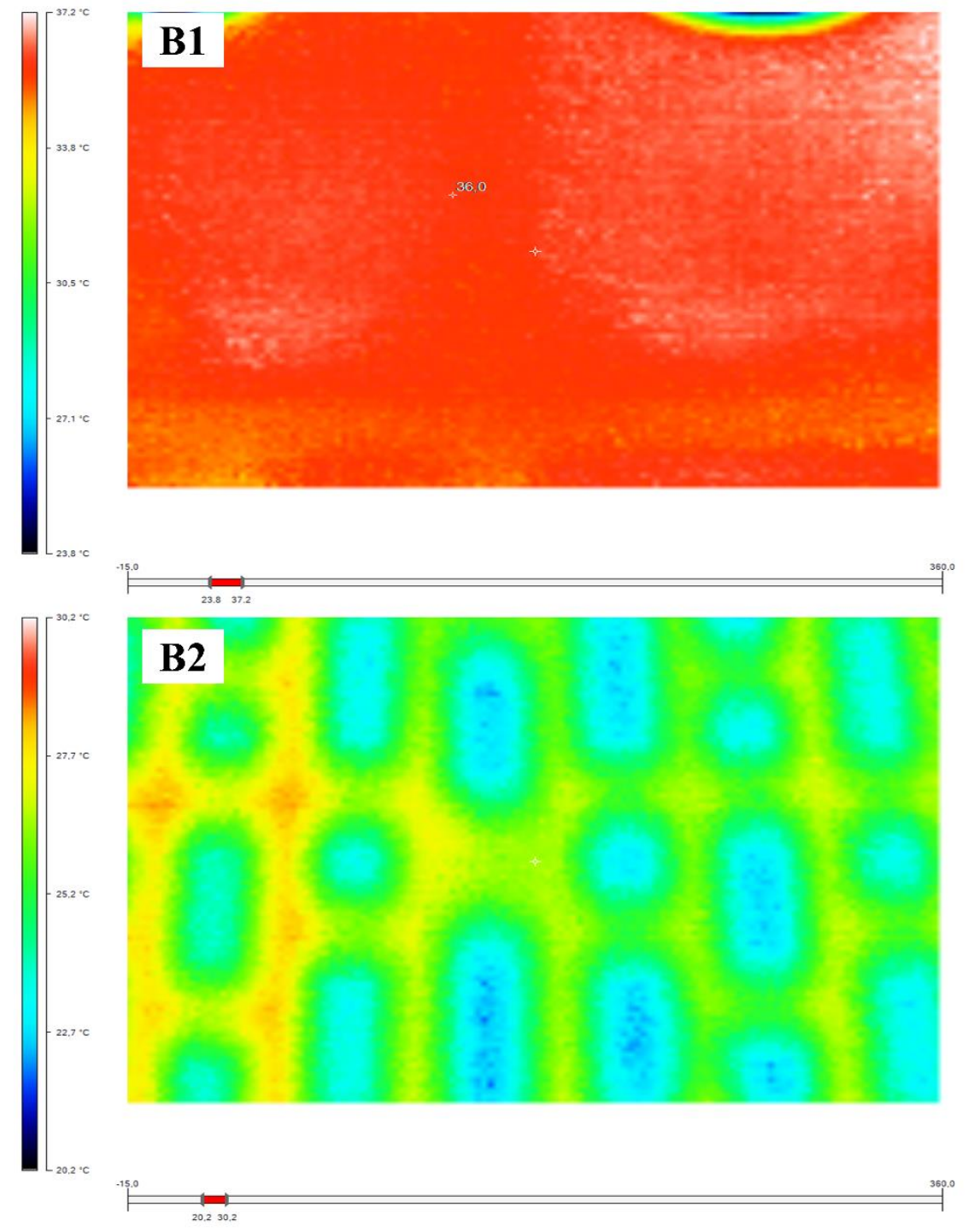

Figura 5. Imagem termográfica da superfície da telha (B1) e na superfície inferior do eco-forro (B2)

Na Figura 6 está apresentada a distribuição de temperatura obtida pelas imagens termográficas da região interna da cobertura. A temperatura média obtida para o bezerreiro $\mathrm{B} 1$ foi de $35,8^{\circ} \mathrm{C}$, com temperatura máxima de $36,6^{\circ} \mathrm{C}$ e mínima de $32,4^{\circ} \mathrm{C}$. Já, para o bezerreiro B2 a temperatura média aferida foi de $25,3^{\circ} \mathrm{C}$, com temperatura máxima de $28,8^{\circ} \mathrm{C}$ e mínima $23,3^{\circ} \mathrm{C}$. Esse resultado indica que o bezerreiro $(\mathrm{B} 2)$ foi $10,5^{\circ} \mathrm{C}$ menor em relação ao bezerreiro (B1), comprovando que o forro atua como barreira térmica.
BARBIRATO et al. (2015) avaliaram bezerreiros cobertos com telhas de fibrocimento associadas ao forro ecológico com placa de isopor® e forro ecológico com placas de espuma PU-mamona durante o período de verão de 2014 e as temperaturas médias obtidas por imagens térmicas foram $28,6^{\circ} \mathrm{C}$ e $28,8^{\circ} \mathrm{C}$, respectivamente. FIORELLI et al. (2010) avaliaram bezerreiros cobertos com telha de fibrocimento com tela de sombreamento, além de bezerreiros com telha de fibrocimento instalado sob sombra durante $o$ período da primavera de 2009 e as 
respectivas temperaturas médias obtidas por imagens térmicas foram $41,4^{\circ} \mathrm{C}$ e $29,8^{\circ} \mathrm{C}$.

Baseado nos resultados obtidos pelas imagens térmicas é possível indicar que o eco-forro amorteceu a transferência de calor e radiação para o interior dos bezerreiros em estudo, ocasionando menores temperaturas internas nesses ambientes. Além disso, a temperatura média do bezerreiro com ecoforro, obtidas por meio de imagens termográficas, mostrou-se inferior aos resultados encontrados em literatura.

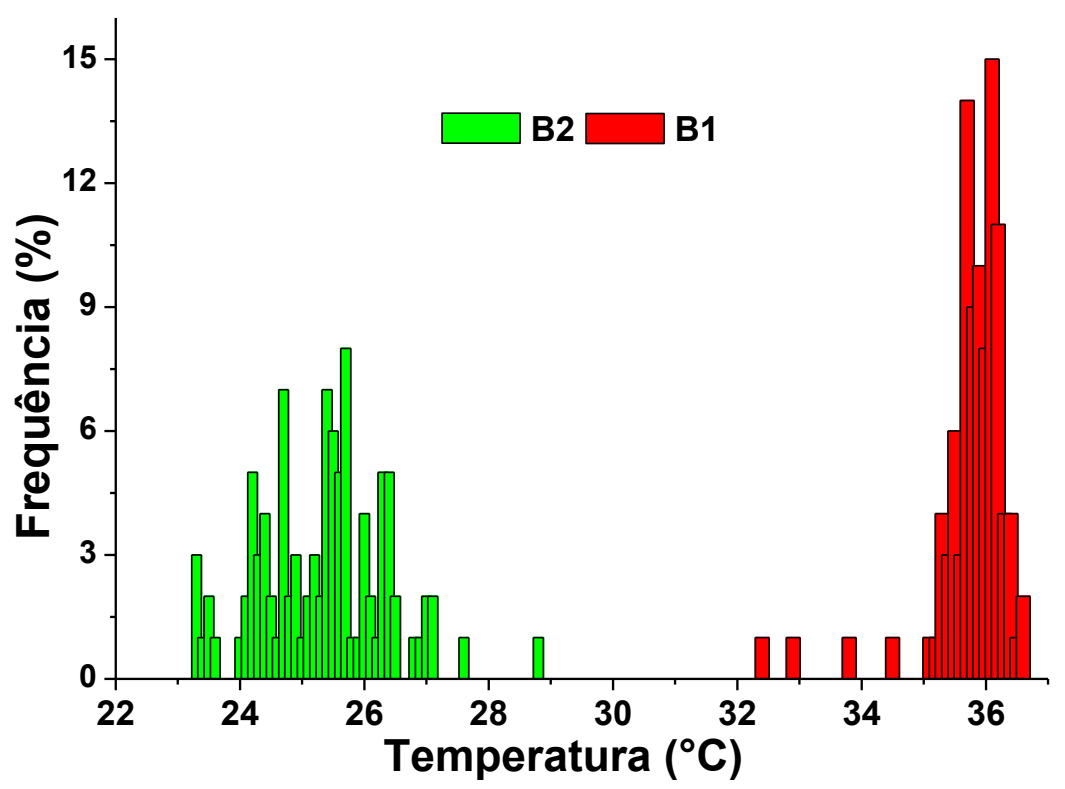

Figura 6. Histograma da distribuição de temperaturas registradas através das imagens termográficas na superfície inferior da telha (B1) e na superfície inferior do eco-forro (B2)

\section{CONCLUSÃO}

Com base nos resultados obtidos podese concluir que o eco-forro de maravalha de Pinus spp. e fibra de sisal apresenta potencial para ser utilizado como forro de bezerreiros. $\mathrm{O}$ uso o eco-forro proporcionou uma redução significativa na temperatura de

\section{AGRADECIMENTOS}

Os autores agradecem o apoio financeiro concedido pela FAPESP (Processo: 2012/18635-0; Processo: 2012/13881-2; Processo: 16/07372-9; Processo:2012/51467-3), CNPq, CAPES, ao

\section{REFERÊNCIAS}

ABREU. P.G; V.M.N. ABREU; A. COLDEBELLA; F.R.F. JAENISCH; D.P. PAIVA. Condições térmicas ambientais e globo negro e nos índices de conforto térmico (CTR e ITGU) de bezerreiros uma vez que permitiu a formação de um colchão de ar sob a cobertura, que atuou como barreira térmica.

programa de pós-graduação em Engenharia e Ciência de Materiais da Universidade São Paulo e ao Núcleo de Pesquisa em Materiais para Biossistemas-BioSMat. desempenho de aves criadas em aviários com e sem o uso de forro. Arq. Bras. Med. 
Vet. Zootec, v.59, n.4, p. 1014 - 1020, 2007.

ARMSTRONG, D. V. Heat Stress Interaction with Shade and Cooling. Journal of Dairy Science, v. 77, n. 7, p. 2044-2050, 1994.

AZEVÊDO, D. M. R.; ALVES, A. A. Bioclimatologia aplicada à produção de bovinos leiteiros nos trópicos. Teresina: Embrapa Meio-Norte, 2009. 83p.

BAÊTA, F.C., SOUZA, C.F. Ambiência em edificações rurais: conforto animal. Imprenta Viçosa, MG: Ed. UFV, 2010, Edição 2. Ed. 269 p.

BARBIRATO, G.; FIORELLI, J.; LINO, G.; CRAVO, J. C. M.; BERTOLINI, M. S.; ROCCO LAHR, F. A. DESEMPENHO TÉRMICO DE BEZERREIROS COBERTOS COM TELHA DE FIBROCIMENTO E FORRO ECOLÓGICO DE SUBPRODUTOS AGROINDÚSTRIAS ASSOCIADO A MATERIAIS ISOLANTES. Revista Brasileira de Engenharia de Biossistemas. v. 9, n. 3, p. 261-267, 2015

BARNABÉ, J. M. C.; PANDORFI, H.; ALMEIDA, G. L. P. de; GUISELINI, C.; JACOB, A. L. Temperatura superficial de materiais utilizados para cobertura individual de bezerreiros. Revista Brasileira de Engenharia Agrícola e Ambiental, v.18, n.5, p. 545-550, 2013.

BUFFINGTON, D.E.; COLLAZOAROCHO, A.; CANTON, G.H.; PITT, D. Black globe-humidity index (BGHI) as comfort equation for dairy cows. Transation of the ASAE, St. Joseph, v.24, n.3, p.711714, 1981.

CABRAL, M.R.; NAKANISHI, E.Y.; FIORELLI, J. Evaluation of the effect of accelerated carbonation in cement-bagasse panels after cycles of wetting and drying. Journal of Materials in Civil Engineering. v. 29, n.6, p. 04017018, 2017.
CABRAL, M.R.; FIORELLI, J.; CRAVO, J.C.M.; SAVASTANO, H. Painéis de partículas com maravalha de Pinus spp. e fibra de sisal. Scientia Forestalis. v. 45, n. 114.2017

CRAVO, J.C.M.; SARTORI, D.L.; NAKANISHI, E.Y.; FIORELLI, J.; BALIEIRO, J.C.C.; SANTOS, W.N. Forro ecológico de resíduos agroindustriais para galpões avícolas. Ciência Rural, Santa Maria, v.44, n.8, p. 1466-1471, 2014

CRAVO, J. C. M.; SARTORI, D. L.; BALIEIRO, J. C. C.; FIORELLI, J. COMPÓSITO À BASE DE RESÍDUOS AGRÍCOLAS PARA APLICAÇÃO COMO FORRO EM AVIÁRIOS. Revista Brasileira de Engenharia de Biossistemas, v. 9, p. 358-367, 2015.

CASTRO, K. N. de C.; COMUNELLO, E.; SOARES, J. P. G.; GABRIEL, A. M. de A.; OLIVEIRA, E. R. de; NEGRÃO, F. J. Características da pecuária leiteira no assentamento Fazenda Nova Lagoa Grande, em Dourados, MS. Dourados: EMBRAPA Agropecuária Oeste, 2010. 44 p. (Documentos, 106). Companhia Nacional de Abastecimento. Agricultura familiar

DIKMEN, S.; HANSEN, P. J. Is the temperature-humidity index the best indicator of heat stress in lactating dairy cows in a subtropical environment? Journal of Dairy Science, v.92, p.109-116, 2009.

EMPRESA BRASILEIRA DE PESQUISA AGROPECUÁRIA. Procedimentos para análise lignocelulósica. Campina Grande: Embrapa Algodão, 2010. 54 p

ESMAY, M. L. Principles of animal environment. 2.ed. Westport CT: ABI Publishing. 1969. 325p.

FIORELLI, J.; SCHMIDT, R.; KAWABATA, C. Y.; OLIVEIRA, C. E. L.; SAVASTANO JÚNIOR, H.; ROSSIGNOLO, J. A. Eficiência térmica de telhas onduladas de fibrocimento aplicadas em abrigos individuais para bezerros 
expostos ao sol e à sombra. Ciência Rural, v.42, p.64-67, 2012.

KAWABATA, C. Y.; CASTRO, R. C. DE; SAVASTANO JÚNIOR, H. Índices de conforto térmico e respostas fisiológicas de bezerros da raça holandesa em bezerreiros individuais com diferentes coberturas. Engenharia Agrícola, v. 25, n. 3, p. 598607, 2005.

MINISTÉRIO DA AGRICULTURA, PECUÁRIA E ABASTECIMENTO.

Projeções do Agronegócio - Brasil Estatística e dados básicos de economia agrícola. Brasília: Departamento de Economia Agrícola, 2017. 53p. Disponível em: www.agricultura.gov.br. Acesso em: 25 jun. 2017.

MENDES, R. F.; MENDES, L. M.; BENEDITO, J. J, G.; MORI, F.A.; CESAR, A, A. Effect of the incorporation of coffee husks on the physico-mechanical properties of Eucalyptus urophylla ST Blake particleboards. Ciência e Agrotecnologia, Lavras, v. 34, n. 2008, p. 610-617, 2010.

NĚMEČKOVÁ, D.; KNÍŽKOVÁ, I.; KUNC, P.; STÁDNÍK, L. The effect of the design of housing systems for calves on the microclimatic conditions of the rearing environment. Arch. Tierzuch. v. 56, p. 509 517, 2013.

STULL, C.; REYNOLDS, J. Calf welfare. Veterinary Clinics of North America: Food Animal Practice, v. 24, p. 191-203, 2008.

TAKAHASHI, L. S.; BILLER, J. D.; TAKAHASHI, K. M. Bioclimatologia Zootécnica. 1. ed. Jaboticabal: Maria de Lourdes Brandel ME, 2009. v. 1. 91p.

TINÔCO, I.F.F. Industrial Aviculture: New Concepts of Materials, Conceptions and Constructive Techniques Available for Brazilian Poultry Houses. Revista Brasileira de Ciência Avícola, v. 3, p. 1-26, 2001.
VASCONCELOS, J.L.M.; DEMÉTRIO, D.G.B. Manejo reprodutivo de vacas sob estresse calórico. Revista Brasileira de Zootecnia (Online), v. 40, p. 396-401, 2011.

VASCONCELOS, J. L. M.; VILELA, E. R.; SÁ FILHO, O. G. Remoção temporária de bezerros em dois momentos do protocolo de sincronização da ovulação GnRH-PGF2 $\alpha$ $B E$ em vacas Nelore pós-parto. Arquivo Brasileiro de Medicina Veterinária e Zootecnia, v. 61, n. 1, p. 95-103, 2009. 